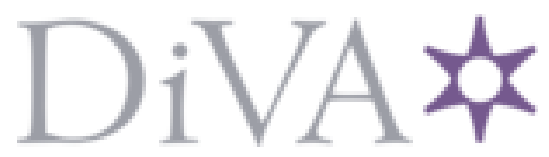

http://www.diva-portal.org

\title{
Postprint
}

This is the accepted version of a paper published in International Journal of Games Based Learning. This paper has been peer-reviewed but does not include the final publisher proof-corrections or journal pagination.

Citation for the original published paper (version of record):

Maivorsdotter, N., Quennerstedt, M., Öhman, M. (2015)

Students' Aesthetic Experiences of Playing Exergames: A Practical Epistemology Analysis of Learning.

International Journal of Games Based Learning, 5(3): 11-24

Access to the published version may require subscription.

N.B. When citing this work, cite the original published paper.

Permanent link to this version:

http://urn.kb.se/resolve?urn=urn:nbn:se:oru:diva-44217 


\section{Students' Aesthetic Experiences of Playing Exergames:}

\section{A Practical Epistemology Analysis of Learning}

Ninitha Maivorsdotter, Örebro University, Sweden

Mikael Quennerstedt, Örebro University, Sweden

Marie Öhman, Örebro University, Sweden

Published in:

International Journal of Game-Based Learning, 5(3), 11-24, July-September 2015

DOI: 10.4018/IJGBL.2015070102 


\section{ABSTRACT}

The aim of this study was to explore Swedish junior high school students meaning-making of participating in exergaming in school based on their aesthetic judgments during game-play. A transactional approach, drawing on the work of John Dewey, was used in the study and the data consisted of video- and audio recordings of ongoing video gaming. A practical epistemology analysis (PEA) was used in order to explore the students' meaning-making in depth. When analyzing the data, the importance of performing well in relation to the challenges the game offers; developing techniques suitable for the game; and interacting socially with one's peers emerged as main themes in the students' meaning-making and learning. It was clear that the students' taste for gaming played a crucial role in how they proceeded in the activity and that meaningful gaming included an intrinsic combination of pleasure and displeasure.

Keywords: Aesthetic Judgments, Exergames, Learning, Meaning-making, Practical Epistemology Analysis

\section{INTRODUCTION}

In this paper we examine how aesthetic experiences - what people find beautiful/ugly and pleasurable/displeasurable - are involved when students play exergames at school. In doing this, we examine the aesthetic aspects that junior high school students experience when playing exergames as a free choice activity in school.

As exergames, such as Wii Fit, Wii Sport and Just Dance, require bodily movement, this type of gaming has attracted an increasing number of physical education (PE) scholars as a subject of research (c.f. Chen, 2013; Sun, 2012). These scholars show that exergaming has the potential to contribute to the PE curriculum by supplementing the current activity options and increasing students' motivation for taking part in PE and physical activity. However, in an overview Ennis 
(2013) points out some of the limitations in this body of research. According to her, scholars have limited their studies to physiological, psychomotor and cognitive meditational variables and have neglected knowledge-oriented educational goals. Ennis (2013) suggests that there is a need to explore exergaming in terms of learning, and in this paper we argue that exploring students' aesthetic experiences of gaming is a fruitful way of responding to this call for research.

Aesthetic experiences are also taken into consideration when exploring learning in other educational disciplines. Research undertaken in the field of science education (Jakobson \& Wickman, 2008; Wickman, 2006) and PE (Maivorsdotter \& Lundvall, 2009; Maivorsdotter, Lundvall \& Quennerstedt, 2014) has shown that aesthetic experiences are involved when students make selections about what is noticed and what is ignored in a certain practice. Cognitive and aesthetic aspects can be explored as entwined when learning is not just seen as a finite, mental outcome, but as part of an often contingent learning process in an activity as a whole. Considering these arguments, it is of interest to empirically examine the role that aesthetic experiences have for meaning-making and learning in exergaming beyond that of motivation.

An approach using a constitutive role of aesthetic experiences in learning gains further support in empirical studies of students in other embodied practices (Maivorsdotter \& Lundvall, 2009; Maivorsdotter, Lundvall \& Quennerstedt, 2014). Here it is shown that learning body movements involves learning a different kind of aesthetics; one that is closely tied to learning how to proceed in the activity and learning the subject content. The situations in which such learning occurs are often aesthetic experiences, where the learner used aesthetic judgments to communicate the directions and preferences of their undertakings. We would argue that there is reason to believe that students taking part in a body movement such as exergaming also use aesthetic judgments as a way of communicating and proceeding during game-play. This line of thought resonates with what Eisner (1976) calls educational connoisseurship. 
The specific role of aesthetic experiences for personal transformation and learning about one's own place in relation to an activity also finds support in socio-culturally oriented studies (Jakobson \& Wickman, 2008). Similar to Eisner's (1976) connoisseurship as being able to differentiate subtleties in a certain practice, Bourdieu (1984) studied the tastes of people with a different upbringing and education. His results suggest that by learning aesthetic distinctions (i.e., taste) education supports the formation of social identity. Hence, learning a certain taste and experiencing aesthetically are not just personal matters, but an important part of being educated within a certain area (Jakobson \& Wickman, 2008), what Gee (2014) in relation to video games talk about as learning to act upon various semiotic domains.

Earlier research in the field of game-based learning suggests that the feedback from objects and the social interactions within and between communities allow the players to build up a better notion of themselves, how they fit into the world and how they can have a positive impact on it through communication (de Freitas, 2013). Drawing from this research, it is clear that learning gaming is a matter of being educated - being a connoisseur - within a certain area and that gaming contributes to the formation of social identity, which, accordingly, means learning a certain taste for gaming. People involved in an educational setting can either accept or reject the 'certain taste' within the setting. They nevertheless have to cope with this taste, and their coping has an impact on their possibility to proceed in the activity. Not accepting or being able to learn the certain taste means not being able to share what is valued and not valued in the activity, which makes it difficult to proceed successfully (Wickman, 2006; Maivorsdotter \& Wickman, 2011).

So, what we find significant in this body of research is that it shows that exergaming has the potential to contribute to learning in different ways. Some of the studies also show that learning is not to be regarded as a personal enterprise, but as building on and shared by others. However, even though the studies include valid findings about the effects and conditions of learning, none 
of the studies empirically show how learning occurs during game-play. Developing knowledge about how learning takes place is crucial when it comes to understanding in-depth learning. The aim of the paper is therefore to contribute to the field by exploring the learning process in exergaming by analyzing the following research questions:

- Which meanings do students make when playing Wii Fit, Wii Sport and Just Dance in school?

- How does the learning process proceed on the basis of students' aesthetic experience of playing?

\section{THEORETICAL FRAMEWORK}

In our study we explore meaning-making and aesthetic experience by using a practical epistemology analysis (Wickman \& Östman, 2002; Maivorsdotter \& Wickman, 2011). This methodology builds on the works of John Dewey, Ludwig Wittgenstein and socio-cultural approaches, where learning is seen as part of a meaning-making process and the units of analysis are actions situated in communication and the activities as a whole (Wertsch, 1995). In this way, communication is investigated as actions-in-context, because when people say something they also do something that has a purpose and consequences (Wickman \& Östman, 2002). Furthermore, we share Lave's (1996) notion of learning as a constantly ongoing process, in which people interact with the world. Since the process is ongoing, our interest is concerned with what direction learning takes in relation to a particular purpose (c.f. Gee, 2014; Rogoff, 1990). Accordingly, learning occurs all the time, but sometimes takes unanticipated paths in undesired directions (Wickman \& Östman, 2002). 
Understanding learning as it has been presented above accords with the work of Dewey, who maintains that experiences are continually transformed in transaction with what occurs, because no two situations are identical. Due to this transformation, people continually learn something new, which is what Dewey (1938/1997) calls the principle of continuity. Dewey (1934/1980) describes experiences in a holistic way, which entails transaction with the situation as a whole, as enacted and undergone as part of an activity with a certain purpose. According to Dewey (1934/1980), every experience and all learning can be understood as not only cognitive, but also as including values, emotions and feelings. In this way, aesthetic experience is an inevitable part of an experience that makes sense. When people decide the direction of their activities, they also pay attention to how they feel about them. Correspondingly, aesthetic judgments about actions also have a normative aspect (i.e., how people should act), which includes what is right and wrong, which relevant entities need to be noted and how to proceed with the act (Jakobson \& Wickman, 2008). Dewey (1934/1980, p. 55) suggests that positive aesthetic experiences are associated with moments of anticipation and moves towards the consummation and fulfillment of activities. Empirical studies have also confirmed this (Jakobson \& Wickman, 2008; Maivorsdotter \& Wickman, 2011) in terms of students making positive aesthetic judgments such as 'great' or 'beautiful' about actions that lead to fulfillment (for example when the basketball hits the basket with a perfect spin). Drawing on this backdrop, it becomes interesting to study aesthetic experiences during game-play, because these experiences deal with students' anticipations of how to proceed and what counts as the fulfillment of purposes and aims, which are normative for action and for what students can learn.

Several studies (Jakobson \& Wickman, 2008; Maivorsdotter \& Wickman, 2011; Maivorsdotter \& Quennerstedt, 2012; Maivorsdotter, Lundvall \& Quennerstedt, 2014) have shown that aesthetic experiences can be studied, because people do not always keep their aesthetic experiences to themselves. Rather, they are regularly communicated and shared as aesthetic 
judgments. In these studies, aesthetic judgments are operationally defined as "utterances or expressions that either deal with feelings or emotions related to experiences of pleasure or displeasure, or that deal with qualities of things, events or actions that cannot be defined as qualities of the object themselves, but rather are evaluations of taste, for example about what is beautiful or ugly" (Wickman, 2006, p. 9). The definition of aesthetic judgments concerning the beautiful/ugly and pleasure/displeasure aligned with Wittgenstein (1966). It is in this connection to language that Wittgenstein functions as an addition to Dewey's principle of continuity. According to Wittgenstein, the meaning of a word or an utterance is its use in a language game, or the activities into which language is woven (Wittgenstein, 1967, p. 5). This also applies to aesthetic judgments (Wittgenstein, 1966, p. 2). So, if we want to find out the meaning of aesthetic experiences, we need to look at how aesthetic judgments are actually used (Wickman, 2006). To sum up, the theoretical framework presented here suggests that by studying how aesthetic judgments take part in furthering exergaming activities, it is possible to study the various ways in which aesthetic experiences influence students' meaning-making and learning of exergaming.

\section{METHODOLOGY}

\section{Data collection}

The study reported in this paper is part of a four-year project funded by the Swedish Research Council with the aim to investigate the learning that takes place when young people play exergames in school. The data for this paper consists of video recordings of ongoing video gaming of two groups of 15-year olds playing exergames once a week for 90 minutes during ten weeks as part of free-choice activity lessons. Four female and three male students volunteered to take part in the study: Emma, Celine, Linda, Nadia, Jonas, David and Simon. Pseudonyms have been used to protect the identity of the participants. Other ethical 
considerations in the study include informed consent, confidentiality by not naming the school or students, security regarding the storage of data and the possibility for students to back out of the study or ask for certain events to be deleted from the video material. All playing sessions were filmed using a stationary camera capturing audio, the players, as well as the screen. In this way spoken communication, embodied actions as well as what happens in the games can be used for the analysis of the learning processes going on.

\section{Data analysis}

In order to select passages in the video data that were rich regarding our research questions, we began the analysis by identifying the exergaming events that were demarcated by the aesthetic qualities expressed. This involved events moving towards an end-in-vew of the aesthetic quality of an experience; events where aesthetic expressions are involved (Dewey, 1934/1980). In his arguments about aesthetics, Shusterman (1986) describes this as aesthetic expressions that are evaluatively colored. In our understanding of Shusterman, aesthetic expressions can appear as words (even swear words), laughter, mimics and gestures. We then searched for aspects of students' exergaming that by means of evaluatively colored expressions moved towards the fulfillment of different purposes or ends-in-view. After this selection of events, the passages were analyzed using a practical epistemology analysis (PEA).

Drawing on the work of Dewey, the later works of Wittgenstein and sociocultural approaches, PEA - in this case with a focus on aesthetic judgments - has been developed for the purpose of analyzing meaning-making processes (Wickman \& Östman, 2002; Maivorsdotter \& Wickman, 2011; Maivorsdotter \& Quennerstedt, 2012; Wickman, 2006; Jakobson \& Wickman, 2008). PEA is designed to explore the direction that meaning-making takes as a result of situated transactions occurring in educational situations. In this study, four PEA concepts were used for 
the in-depth analysis, namely (i) purpose, (ii) gaps, (iii) relations and (iv) encounters. The analysis was conducted in the following way:

First step. PEA starts by trying to identify the (i) purposes of the activity to be explored. In this analysis, the first step includes ascertaining the purposes for the students' participation in the particular activity.

Second step. After having identified the purposes for the students' participation, the next step in the analysis is to identify (ii) gaps that emerge from these purposes. For example, if a student's purpose is to manage the track and reach high scores in the game, this could be said to open up a gap between the student's desire to reach high scores in the game and the actual outcome.

Third step. In order to continue the actions, the student has to fill the gap of managing the track and getting high scores in the game with (iii) relations. Accordingly, the next step in the analysis is to identify the various kinds of relations that the students use to fill the identified gaps. Several studies (Maivorsdotter \& Wickman, 2011; Jakobson \& Wickman, 2008; Wickman, 2006; Maivorsdotter \& Quennerstedt, 2012) show that people make aesthetic judgments when making meaning of an experience that moves towards fulfillment (having a positive aesthetic experience) or away from it (having a negative aesthetic experience). For example, if the student makes the aesthetic judgment 'I'm great', we can see that the student experiences the gaming as moving towards the fulfillment of his purpose of having a positive experience of the game. Aesthetic judgments thus provide us with information about how the student judges her or his possibility to successfully participate in the game. Hence, a relation is a statement or utterance that construes a connection between the entities of experience. A relation concerns what the case is or how certain things are valued. In this step, the identified relations are categorized into themes. 
Fourth step. In constructing relations, the students describe some of the things that they encounter in these experiences. For example, these (iv) encounters could involve fellow students, what happens in the game and the students' previous experiences. The relations that are construed when the students describe different encounters illuminate the connection between the student and the situation as a whole.

The four analytical steps proceeded in the following way: The researchers selected aesthetic events separately and then brought their findings into a common selection of events. Together the researchers then identified the purposes of each event (step 1), going back and forth in the selected event, as well as going back to the whole data collection when needed. This process was followed by a next step in which the researchers identified gaps in relation to the identified purposes (step 2). The analysis then continued by identifying relations including aesthetic judgments that the student used to fill these gaps. These relations was emphasized in the transcript followed by a process in which the selected relations were categorized into themes (step 3). In the events, the students made several relations, but the analysis - drawing from the theoretical framework in this study - was only made on relations including aesthetic judgments. One of the researchers made the first categorization of relations, and the analysis was then confirmed by the others including minor changes and clarifications. The identified themes included the major part of the selected relations. The few excluded relations where either too small by number, too vague in linguistic terms, or hard to interpret in relation to the aim of the study. Finally, the identified themes were analyzed with focus on encounters (step 4). This step involved all the researchers deliberating the explored events as a whole.

\section{Trusworthiness}

It has been argued by Kirk and Miller (1986) that two ways to attain trustworthiness in qualitative research is that: 
a. the study is reported in a detailed and accessible manner so that it may be replicated,

b. the results of the study are reported in a transparent way in terms of theoretically meaningful variables.

We have addressed each of these demands when reporting this study in terms of clarity in our theoretical assumptions as well as ensuring that the research procedure for this study has been documented in a detailed and clear manner (Minichiello et al., 1995). In the analytical phase of the study we have further, in line with Lincon and Guba's (1985) suggestion regarding 'peer debriefing', deliberately used the second and third authors of the paper to critically scrutinize the initial analysis made by the first author. In this way we have followed Bogden and Biklen (1998) in their suggestion that debriefers can reduce the risk of researcher bias.

However, Merriam (1998) questions the generalizability of outcomes from a single case to a larger population. It is acknowledged in this study that small qualitative studies are not generalizable in the more conventional sense. However, it is also argued that studies such as this have laudable qualities (Flyvbjerg, 2006). In this study, the generalizability of the research does not emanate from how representative the sample might be, but from the way in which the experiences are likely to be reasonable to other groups in similar contexts. That the findings are context-dependent is not regarded as a limitation. Previous research shows the need for disciplines to develop on the basis of the systematic production of exemplars and that good examples are by nature context-dependent (Flyvbjerg, 2006). It can be argued that the strength of the qualitative approach employed in this study is the depth of exploration and description, which produces a vivid and detailed understanding of the idiosyncrasies of the situation under investigation (Chambers \& Armour, 2012).

\section{FINDINGS}


The identified themes in the study are: (i) Performing well in relation to the challenges the game offers, (ii) Developing techniques suitable for the game and (iii) Interacting socially with your peers.

\section{Performing well in relation to the challenges the game offers}

When exploring the relations that the students make when playing exergames, the importance of performing well in relation to the challenges of the game was identified as an important theme. This theme is based on both positive and negative aesthetic experiences. If the challenge is attractive and is in line with the students' taste for gaming, the game can be defined as a positive challenge (even if it includes feelings of frustration and joy) that can be continued. However, if the challenge is not in line with the students' taste for gaming, they make negative aesthetic judgments and soon stop playing the game.

In the following excerpt we can see how a student makes meaning of playing Wii Fit. In this aesthetic event, Jonas $(\mathrm{J})$ is playing the game standing on a balance board, whereas his peer David (D) and the scholar Clint (C) are watching. Jonas has managed the first level and is now going to try the next in terms of playing a new track.

1) J: You know what, I'm damned good at this! [ $\mathrm{J}$ begins the next track]

2) J: Damn, what the devil.

3) C: [unclear]... everything at the same time

4) J: Run then. Oh, damn.

5) D: Can the runner turn?

6) C: No, no. It just runs straight on.

7) [The avatar dies.]

8) J: No, god how stupid. [Turns to D and M.] Don't laugh!

9) J: Run then you ol' devil. 
10) [The avatar dies.]

11) J: But, for god's sake [laughs]. Bloody stupid game.

12) J: Now goddam it, run now. Looks like a penguin when it runs. Jump now then!

13) D: Oh, run. Jump!

14) J: Jump for godsake [laughs].

15) [The avatar dies.]

16) J: Bloody bad luck mate.

17) J: Hell. [Laughs] Damned stupid game.

18) [On the screen: Finished.]

Jonas participates in the game for the purpose of managing the entire track in order to reach the next level. This purpose opens up a gap between Jonas' desire to manage the track successfully and how the game turns out in the end. Jonas fills this gap with relations by making the aesthetic judgment (1) "I'm damned good at this" and showing that he experiences himself as having the right capability to manage this track. In his opinion, the fulfillment of the purpose is within reach. However, Jonas soon realizes that the fulfillment of the purpose is more difficult to reach than he had expected. In line (4) he tells the avatar to run, followed by the aesthetic judgment "Oh, damn" when the avatar is almost hit by a rolling tree trunk. When the avatar 'dies' (7) Jonas makes the following relation "no, god, how stupid" (8), showing that the death of the avatar is an action that leads away from fulfillment of the game. This pattern of action - the avatar 'dies' (lines 10 and 15) and Jonas making negative aesthetic judgments in terms of swear words (lines 11, 16 and 17) - are repeated twice before the session ends. In this aesthetic event, Jonas fills the gap between managing the whole track and how the game turns out in the end with relations by making negative aesthetic judgments. However, an aesthetic experience is a complex emotional experience. In 
connection with the negative aesthetic judgments (the swear words) Jonas laughs and expresses joy. It is thus clear that Jonas is having a positive aesthetic experience at the same time as he is frustrated about not being able to manage the track successfully. In his way of making meaning of his experience, the encounter with the game ends up in an emotional experience, where pleasure and displeasure add an aesthetic quality to the game.

After analyzing the purpose of Jonas' participation, the importance of managing the whole track in order to reach the next level is identified. This purpose opens up a gap between Jonas' wish to manage the whole track and how the game turns out in the end. In the encounter with the game, Jonas fills this gap with relations that mainly relate to the possibility to perform well given the challenges the game offers. For instance, this way of making meaning of the game is visible in line 1, where Jonas judges himself as being able to perform well. Another way of meaning-making is visible in line 8, where Jonas judges his actions to be leading in the wrong direction, based on the fact that the avatar 'dies'; something that happens when the player does not perform well in relation to the challenges of the game. When analyzing Jonas' way of making meaning of his gaming experience, actions that lead to the 'death' of the avatar are negative aesthetic experiences which detract from his fulfillment of the game (8, 11 and 16). However, based on Jonas' laughter (11, 14 and 17), these actions are also judged as joyful. The mix of frustration and joy in this excerpt are reasonable in the light of a certain kind of taste for gaming. Although his actions lead in the wrong direction, Jonas has no problem making meaning of the challenges offered by the game. He quickly understands what it takes, and even though he cannot manage all the challenges at once, the rapid feedback about which actions lead the avatar in the right or wrong direction (the avatar either continues to run or falls off the track) tells him how to proceed. In this aesthetic event, we can see how Jonas has difficulty managing the content of body control (balance and reaction), but that he has no problem grasping content concerning aims and procedures. 
But what happens if the player does not agree with the value of the challenges of the game? In the next event we can see how Jonas finally understands what the challenge is, but rejects the value of it. This event is taken from a session in which Jonas (J) and David (D) are playing Wii Fit with the inclusion of a body test. In this part of the event, Jonas is standing on the balance board and has just weighed in and performed balance tests involving moving his body weight back and forth on the balance board. David is sitting beside him looking at the screen.

19) J: Who is best? Who is best?

20) [On the screen: BMI test result]

21) J: What the hell is that?

22) [The avatar is fat.]

23) D: Oh my.

24) J: What!

25) D: [Laughs] What a belly.

26) J: [Reads from the screen.] At risk [wrinkles his nose]. Naaw.

27) D: [Laughs]

28) J: They're stupid.

29) [New information on the screen.]

30) J: My god they're so stupid.

31) D: [Laughs]

32) [New information on the screen.]

33) J: What's happening now?

34) J: Am I that fat for godsake?

35) J: I've got muscles you know.

36) [New information on the screen.]

37) J: Hell no. Can't be overweight. 
38) D: [laughs]

In this aesthetic event, the purpose is to manage the challenges of the game successfully. This purpose opens up a gap concerning the players' wish to succeed and how the gaming turns out in the end. Jonas and his peer David fill this gap with the following relations: Jonas begins by making the aesthetic judgment 'who is best' (19) pointing at himself as being capable of managing the challenge. However, his feeling of trust quickly turns to confusion when he sees the 'BMI test result' on the screen and says 'what the hell is that' (21), showing that the fulfillment of the situation has now turned in the opposite direction. When the avatar gets bigger - to illustrate that Jonas has an above average BMI - Jonas and David begin to understand that the challenge in this game is not about immediate action, but having a desirable BMI. Depending on their different positions in the game, 'side-kick' David makes the aesthetic judgment of laughing $(25,27$ and 31) and his tone and mimicking express that the situation is still moving towards fulfillment. Jonas, on the other hand, gives the opposite impression. His aesthetic judgments 'they are stupid' (28) and 'my god they are so stupid' (30) show that he finds the situation unpleasant. The challenge of getting a lower BMI is unattractive to him and he continues by saying: 'Am I that fat for godsake? I've got muscles you know.' (34 and 35) The fat avatar on the screen and the somber music communicate to the player that he has failed to manage the challenge of normal weight. In the encounter with this part of the game (testing BMI), the player has a negative aesthetic experience. In the remainder of the videotaped events neither of the boys returns to this part of the game.

The relations made by Jonas and David can be categorized as concerning the possibility to perform well in relation to the challenges of the game. Both Jonas and David realize that Jonas performs badly in relation to the challenge of the game. Depending on his position in the game, Jonas expresses a negative aesthetic experience, whereas David expresses the opposite. Jonas' negative aesthetic experience of the BMI result naturally has a negative 
impact on his willingness to proceed. In this excerpt, we can see that both Jonas and David grasp the content of the game in terms of understanding the purpose of the challenge. The idea of the game seems to be that the player has to realize the connection between exercise, weight loss and normal weight, but because Jonas (and later on even David) does not value the challenge as something desirable, he does not continue this learning process. In order to perform well in this respect Jonas has to exercise (such as that offered by the game) regularly and then repeat the BMI test. According to Jonas' aesthetic judgments when playing the game, this kind of game does not fit with his taste for gaming at all.

\section{Developing techniques suitable for the game}

This theme contains students' meaning-making of how to develop techniques in order to manage the game. In this setting, 'techniques' range from being able to control actions on the screen - for instance the movements of an avatar - by means of a hand control to balancing on a balance board. Different parts of the Wii Fit, Wii Sport and Just Dance exergames use this equipment in different ways, and the students' development of technique concerns the same relation, namely the relation between their own actions, how they are registered by the equipment and the actions on the screen. In this setting, in order to succeed the students have to develop techniques that are suitable for the game.

This can be seen in the following aesthetic event, where Ellen (E) guides her peers Celine (C) and Nadia $(\mathrm{N})$ in the performance of a dance in Just Dance 2. In this event, Ellen makes the same aesthetic judgments that appear on the screen, for example 'lazy' or 'perfect', and tries to master the technique by copying the movements of the avatars on the screen. This means that she is more concerned about the relation between the players and the avatars than by her peers' dancing moves. The two girls are focused on the screen and Ellen switches between looking at her peers and looking at the screen. 
39) E: Give it all you've got, girls. More attitude Nadia. Don't be lazy.

40) E: Look. You're pefect nu. Not lazy.

41) E: Come on. More! Keep it up.

42) E: Come on girls.

43) E: Keep it up, Celine. You're a bit behind.

44) E: More. Come on. More go.

45) E: Bit more feeling Nadia.

46) C: [Laughs]

47) E: Bit more feeling. Ah, that's brill.

48) E: Good artist.

49) C: [Unclear]

50) E: Good on ya girls. Get stuck in Nadia. No lazy bones here.

51) E [Laughter] You just [copies Celine's movements].

52) E: Great girls.

53) E: It's got to be perfect.

The purpose of participation in this event is to copy the moves of the avatar on the screen as closely as possible. This purpose opens up a gap between the students' wish to dance and how the dancing turns out in the end. In this event we focus on Ellen's meaning-making, because she is the one that expresses clear aesthetic judgments. After pushing her peers to try harder in lines 39 to 46, Ellen expresses that her peers are moving towards fulfillment in the dance by making the aesthetic judgment 'Ah, that's brill' (47). 'Brill' in this case means working at the same high tempo as the avatar and synchronizing the hand control with the avatar's moves. In the next line, Ellen makes the aesthetic judgment 'good artist' (48). Although the meaning of this judgment is not totally clear, it tells us that the dance is going in the right direction according to Ellen. The avatars on the screen make expressive and large movements, whereas the 
movements of the dancing students are much more limited. Despite the differences in the performances of the avatars on the screen and the girls in the room, the girls still seem to deserve the aesthetic judgment 'brill' from Ellen. Ellen then makes the following relations 'great girls' (52) and 'it's got to be perfect' (53), thus showing that the actions are still moving toward fulfillment. The final judgment 'perfect' (53) is in line with the judgment of the players' performance on the screen. By making this aesthetic judgment, Ellen sheds light on the importance of managing the hand control in relation to the movements of the avatar - it is that relation that is judged as 'perfect' both by Ellen and by the game.

In this aesthetic event we can see how the theme developing techniques suitable for the game is created in Ellen's way of making meaning of playing Just Dance. This is a positive aesthetic experience, where the development of technique and being able to proceed with the learning process means being able to synchronize the hand control with the movements of the avatar. In order to improve her peers' techniques, Ellen encourages them to work harder and to move with passion, but in the end 'perfect' means actions that render the level 'perfect' on the screen. That this content of body movement is in line with the students' taste for gaming is shown by the aesthetic judgments made by Ellen. This is also evident in the video material as a whole, where the female students play the Just Dance exergame with great enthusiasm.

In the former aesthetic event, the students have no problem understanding which kind of technique is suitable for the game. However, in the next event, neither Nadia (N) nor Celine (C) understand how to proceed, and as a result their learning processes quickly take another direction (in terms of ending this part of the game and continuing with another part) after they fail to manage the relation between Celine's actions and what is happening on the screen. Their encounter with this part of Wii Fit turns out to be a negative aesthetic experience. In this excerpt, Celine is sitting on the balance board doing yoga and Nadia is sitting on a table watching the game. 
54) C: I'll do it once more.

55) N: Oh, are we supposed to hold that thing. The light. It should go out.

56) C: Hum, it's really hard.

57) [New instructions on the screen.]

58) N: Am I supposed to sit still!?

59) C: Yes.

60) G: Let us begin.

61) [Sound of crickets.] [Sound of footsteps.]

62) $\mathrm{N}$ : What a horrible noise. [Moves closer to the wall.]

63) G: Faults.

64) C: But! What! I'm sitting still!

65) G: Close the session.

66) C: Bugger! Blimey! [Unclear.]

67) [C gets up from the balance board.]

68) C: Do you know how difficult that was?

The purpose of participating in this aesthetic event is for Celine to manage the session successfully and receive some kind of assessment of her performance (high score or reach a new level). This purpose opens up a gap between the students' wish to succeed and how the game turns out in the end. Celine and Nadia fill this gap with relations concerning how Celine should manage the game. The relations include meaning-making about what kind of challenge this is, as well as which kind of technique is most suitable for this challenge. To begin with, Nadia suggests that the challenge is to get the light to go out (55). This suggestion renders the aesthetic judgment 'really hard' (56) from Celine, which indicates that this action is hard to fulfill. At the beginning the two girls fill the gap with relations that in actual fact lead away from the fulfillment of the game. However, after reading the instructions on the screen, Celine 
and Nadia realize that the challenge is to keep the light shining. However, grasping this content does not seem to make the game more pleasurable. When hearing the sound of crickets and footsteps, Nadia seems to be frightened and utters the negative aesthetic judgment 'what a horrible noise' (62). As can be seen in the following, understanding the challenge does not mean that Celine can use a suitable technique to master the challenge. Even though she - in her opinion (64) - is sitting still, the game judges her actions as unsuccessful (64 and 66). In order to fulfill the purpose of her participation in the game, Celine has to continue to develop her technique; a learning process that is not attractive to her. By using the negative aesthetic judgments of swear words (66) and asking 'do you know how difficult that was?' (68) before ending the game, Celine makes it clear that this type of challenge and technique does not align with her taste for gaming.

The importance of developing techniques that are suitable for the game is visible in this aesthetic event. After reading the instructions (57) the students realize that the most suitable technique is to keep calm and quietly balance on the balance board. However, drawing on their negative aesthetical judgments when playing the game (62, 66 and 68$)$, it is clear that both students find this action unappealing and that the negative aesthetic experience illustrates their willingness to proceed. In the encounter with the game, Celine and Nadia can (after a while) grasp the content in terms of understanding the aim and procedure of the game. However, as Celine is unable to manage the content in terms of body control and Nadia finds the sounds scary (62), understanding what kind of technique has to be developed is not enough to proceed with the activity. The technique also has to have an attractive quality in order to inform the learning process. When that is not the case, the learning process turns in another direction, which in this case is the termination of this part of the game.

\section{Interacting socially with your peers}


When analyzing the relations made by the students when making meaning of their participation, the third significant theme that is identified is interacting socially with your peers. As can be seen from the earlier excerpt, interacting socially with peers is involved in all the analyzed events. In some events the social interaction is a minor issue, while in others it is a major one. In the event that follows, we can see how Jonas (J) and Simon (S) interact in the canoeing game. Here, the students are sitting on chairs and holding the hand controls in their hands. As they are not very familiar with the game their arm movements are somewhat exaggerated, which is not the most effective way of maneuvering the canoe on the screen. However, this problem does not seem to bother them and they express great joy during the game.

69) [The game begins again. J and S paddle intensively.]

70) J: Bit it's [unclear]. Bugger.

71) S: Yes!

72) S: Yes, I'm going to win [laughs].

73) S: Oh my god.

74) S: No, no [laughs].

75) J: It worked. [Makes a victory sign.] Yeah. Win!

76) S [Laughs]

77) J: Gosh, that was great.

78) [J and S laugh.]

79) J: That was fun.

80) S: [Laughs] Yes. [Takes his smart phone out of his trouser pockets.]

81) J: What? [Looks at the screen on S's phone.]

82) S: What the hell. [Looks at the screen.]

83) J: You know what. We'll play the other one. 
84) [J and S switch games.]

When analyzing this aesthetic event, the purpose of participation is for Jonas and Simon to interact joyfully together. The emotional aspect of being peers is seen to be more important than how the playing develops in terms of who wins the game. This purpose of participation opens up a gap between the hope of a joyful interaction and how the interaction turns out in the end, which Jonas and Simon fill with the following relations: At first Jonas uses the aesthetic judgment 'bugger' (70), but because the rest is difficult to hear, we cannot decide whether this is a positive or negative aesthetic judgment. In response Simon says 'yes, I'm going to win' (72) and his laughter (72) shows that this is an aesthetic judgment that the action is going in the right direction. However, winning the game is not the most important thing. This is shown in the following lines where Simon says 'oh my god' (73) and 'no, no' (74). With these judgments Simon shows that the game is now leading in the wrong direction - he is going to lose - although the aesthetic expression of laughter (74) shows that the action of gaming is still leading towards fulfillment. The purpose of participation in this event is to interact joyfully with his peer. Losing the game does not mean that Simon cannot interact joyfully with Jonas. The end of this gaming session also supports this interpretation. At the end Jonas says 'gosh, that was great', (77) and 'that was fun' (79), and Simon agrees with these aesthetic judgments by saying 'yes' and laughing (80). Despite this being their first canoeing session, the students end this part of Wii Sport and switch to another sport after having fulfilled the purpose of interacting joyfully together.

In this event, two of the working themes are visible: the theme of performing well in relation to the challenges offered by the game (line 72, where Simon says 'yes, I'm going to win' and laughs) and that of interacting socially with your peers. However, the main theme in this event 
is interacting socially with your peers. The purpose of participation - interacting joyfully together - maps this particular theme. How do the students' ways of making meaning of this event influence their willingness to proceed with the activity? As can be seen from the analysis, both students experience what it takes to interact joyfully. Simon laughs even when he does not win. He shows that he understands that if he loses his temper when losing the game the joyful interaction may end, and he can control himself enough to cope with being the runner-up in the game. Wining is not essential here. In the students' encounters with the game, both Simon and Jonas have positive aesthetic experiences of the game in terms of having a joyful time together. As the students make more meaning of their social interaction in this event - compared to some of the other events in this paper - they make less meaning of the challenges offered by the game or how to develop technique suitable for the game. Clearly, this way of making meaning of the event influences the students' willingness to proceed. As no gaming challenge or gaming technique is at stake in this event, the students can easily switch to another part of the game after finishing their first race. Jonas' positive aesthetic judgment 'that was fun' (79) refers to their interaction with each other, not to their interaction with this part of the game. One conclusion that can be drawn is that positive aesthetic experiences of gaming do not mean that the students simply continue to play. In order to be interesting the gaming experience has to be more complex - as in the first event in this paper - if it is to lead to further gaming. An aesthetic experience of gaming with an interesting aesthetic quality includes a combination of pleasure and displeasure.

\section{CONCLUSION}

In this paper we explore the learning process in exergaming by analyzing which meanings students make when playing and how the learning process proceed on the basis of the students' aesthetic experiences. Our findings show that the meanings that students make are (i) performing well in relation to the challenges the game offers, (ii) developing techniques suitable 
for the game and (iii) interacting socially with peers. The result shows that the students taste for gaming determines how the learning process proceeds (c.f. Bourdieu, 1984). If the direction of the game does not appeal to the students, they end the game rather quickly. This is visible in yoga where the challenge is to sit absolutely still on the balance board and in the BMI test where the challenge is to lose weight and gain a desirable BMI. On the contrary, the taste for gaming is visible when playing the track and the dance games. Challenges and the improvement of techniques, including rapid, reasonable and clear feedback of which action leads to fulfillment, are experienced as meaningful. If the students do not find that the challenges or the techniques suitable for the game align with their taste for gaming, the game does not succeed in leading the students to further gaming.

Importantly, we can understand the students' learning through their aesthetic experience (c.f. Dewey, 1934/1980; Eisner, 1976). Feelings such as frustration and joy can accordingly be part of the same aesthetic experience and add an aesthetic quality that supports the learning process, as long as the students experience the challenge as meaningful. In this way, the learning process is not restricted to behavioristic notions of learning, but instead more complex, guided by students taste for gaming. We would argue that understanding how the learning process proceeds is an important aspect when it comes to developing research on game-based learning (Wickman \& Östman, 2002), and in this paper we have demonstrated one way of studying the learning process in game play by analyzing the aesthetic judgments that the students make when playing. The article consequently contributes to both methodology development and knowledge about learning processes in exergaming.

\section{REFERENCES}

Bogden, R.C., \& Biklen, S.K. (1998). Qualitative research for education: An introduction to theory and methods. London, UK: Allyn and Bacon. 
Bourdieu, P. (1984). Distinction: A social critique of the judgement of taste, London, UK: Routledge.

Chambers, F., \& Armour, K. (2012). School-university partnerships and physical education teacher education student learning: A fruitful division of labour? European Physical Education Review, 18(2), 159-181. doi: 10.1177/1356336X12440023

Chen, A. (2013). Effects of exergaming and the physical education curriculum. Journal of Sport and Health Science, 2(3), 129-130.

de Freitas, S. (2013). Towards a new learning: Play and game-based approaches to education. International Journal of Game-Based Learning, 3(4), 1-6. doi: 10.4018/ijgbl.2013100101

Dewey, J. (1934/1980). Art as experience. New York, NY: Perigee Books.

Dewey, J. (1938/1997). Experience and education. New York, NY: Touchstone.

Eisner, E. W. (1976). Educational connoisseurship and criticism: Their form and functions in educational evaluation. Journal of Aesthetic Education, 10(3/4), 135-150.

Ennis, C. D. (2013). Implications of exergaming for the physical education curriculum in the 21st century. Journal of Sport and Health Science, 2(3), 152-157.

doi:10.1016/j.jshs.2013.02.004

Flyvbjerg, B. (2006). Five misunderstandings about case-study research. Qualitative Inquiry, 12(2), 219-245. doi: 10.1177/1077800405284363

Gee, J. P. (2014). What video games have to teach us about learning and literacy. New York, NY: Palgrave Macmillan. 
Jakobson, B., \& Wickman, P.-O. (2008). The roles of aesthetic experience in elementary school science. Research in Science Education, 38 (1), 45-65. doi: 10.1007/s11165-007-90398

Kirk, J., \& Miller, M. L. (1986). Reliability and validity in qualitative research. London, UK: Sage.

Lave, J. (1996). The practice of learning. Cambridge, UK: Cambridge University Press.

Lincoln, Y.S., \& Guba, E.G. (1985). Naturalistic Inquiry. London, UK: Sage.

Maivorsdotter, N., \& Lundvall, S. (2009). Aesthetic experience as an aspect of embodied learning: Stories from physical education student teachers. Sport, Education and Society, 14(3), 265- 279. doi:10.1080/13573320903037622

Maivorsdotter, N., \& Wickman, P.-O. (2011). Skating in a life context: Examining the significance of aesthetic experience in sport using practical epistemology analysis. Sport, Education and Society, 16(5), 613-628. doi:10.1080/13573322.2011.601141

Maivorsdotter, N., \& Quennerstedt, M. (2012). The act of running: A practical epistemology analysis of aesthetic experience in sport. Qualitative Research in Sport, Exercise and Health, 4(3), 362-381. doi:10.1080/2159676X.2012.693528

Maivorsdotter, N., Lundvall, S., \& Quennerstedt, M. (2014). Being a competent athlete or a competent teacher?: Aesthetic experiences in physical education teacher education. European Physical Education Review, 20(3), 407-422. doi:10.1177/1356336X14535058

Merriam, S. B. (1998). Qualitative research and case study applications in education. San Fransisco, CA: Jossey Bass. 
Minichiello, V., Aroni, R., \& Timewell, E. (1995). In-depth interviewing: Principles, techniques, analysis. South Melbourne, VIC: Addison Wesley Longman.

Rogoff, B. (1990). Apprenticeship in thinking: Cognitive development in social context. Oxford, UK: Oxford University Press.

Shusterman, R. (1986). Wittgenstein and critical reasoning. Philosophy and Phenomenological Research, 47(1), 91-110.

Sun, H. (2012). Exergaming impact on physical activity and interest in elementary school children. Research Quarterly for Exercise and Sport, 83(2), 212-220. doi:10.1080/02701367.2012.10599852

Wertsch, J. V. (1995). The need for action in sociocultural research. In J. V. Wertsch, P. del Río, \& A. Alvarez (Eds.), Sociocultural studies of mind (pp. 56-74). Cambridge, UK: Cambridge University Press.

Wickman, P.-O. (2006). Aesthetic experience in science education: Learning and meaningmaking as situated talk and action, Mahwah, NJ: Lawrence Erlbaum Associates.

Wickman, P.-O., \& Östman, L. (2002). Learning as discourse change: A sociocultural mechanism. Science Education, 86 (5), 601-623. doi: 10.1002/sce.10036

Wittgenstein, L. (1966). Lectures and conversations on esthetics, psychology and religious belief. Oxford, UK: Blackwell.

Wittgenstein, L. (1967). Philosophical investigations. Oxford, UK: Blackwell. 
